\title{
Micro-grid Stability Analysis under the Grid Fault Condition
}

\author{
Tian-Yi MA ${ }^{a,{ }^{*}}$, Ming-Ming ZHANG and Jin-Yao LI \\ Beijing Institute of Graphic Communication, Beijing, China \\ amatianyi@bigc.edu.cn \\ ${ }^{*}$ Corresponding author
}

Keywords: Micro-grid, Micro-Source, Stability; Grid Fault, Grid-connected Mode.

\begin{abstract}
Micro-grid have two kinds of working mode, which are the grid-connecting mode and islanding mode. In order to ensure the important load work safety, when the grid occur a big fault, the micro-grid should get out of the grid-connecting mode and work alone. Under this condition, it's important to decide the effect caused by different kinds of fault, in order to decide whether to islanding mode. This paper firstly analysis the most important reason affect micro-grid stability, presents a 3-Bus micro-grid system and carried out 9 cases of grid fault simulation. Based on the simulation result, the effect caused by different kinds of grid fault is concluded, and the stability improve suggestion is also given.
\end{abstract}

\section{Introduction}

The micro-grid is formed by multiple micro-sources and load, which has two operating modes, grid-connecting mode and islanding mode. Normally, the micro-grid is operated under grid connected mode. When faults occur in main grid, the micro-grid will disconnects from the main grid and works under islanding mode.

The micro-sources are mostly interfaced by converter. According to the operating method, the converter can be divided into two types, the supporting micro-source and the feeding micro-source. Usually, the first kind of micro-source is controlled by droop method, and the second kind of micro-source is controlled by PQ method[1-3]. As the droop control converter can support the micro-grid voltage and frequency during the islanding mode, a lot of papers pay much attention to the stability analysis of the droop control converter. Paper[4] proposes a kind of small signal model for the converter connecting with grid, and the key parameter affect system stability is carried out based on the root locus result. The influence of communication delay on the stability of micro-paper [5]-[6], these papers shows the small signal model of multiple converters, and the root locus result of is also carried out. Paper [7] shows the small signal model of islanding micro-grid using the common rotation coordinate transformation method, the dynamic response characteristics of the system are designed by calculating root locus of this model.

\section{The Micro-grid Topology}

There are a variety of micro-sources in the micro-grid, and the micro-sources are usually connected with the main power grid by converters. According to the different control mode of the converters, they can be divided into two kinds: the voltage source control mode converter(VSC-MC) and the current source control mode converter(CSC-MC). Usually, the VSC-MC is controlled by droop method and the CSC-MC is controlled by PQ method. The droop control method and PQ control method is shown in Fig.1.

In order to analysis the stability of micro-grid under grid fault condition, this paper present a micro-grid formed by multiple VSC-MC and CSC-MC. The micro-grid is shown in Fig.2. In this figure, CB represents the circuit breaker, L represents the static load of micro-grid, and TL represents the transmission line of micro-grid. 

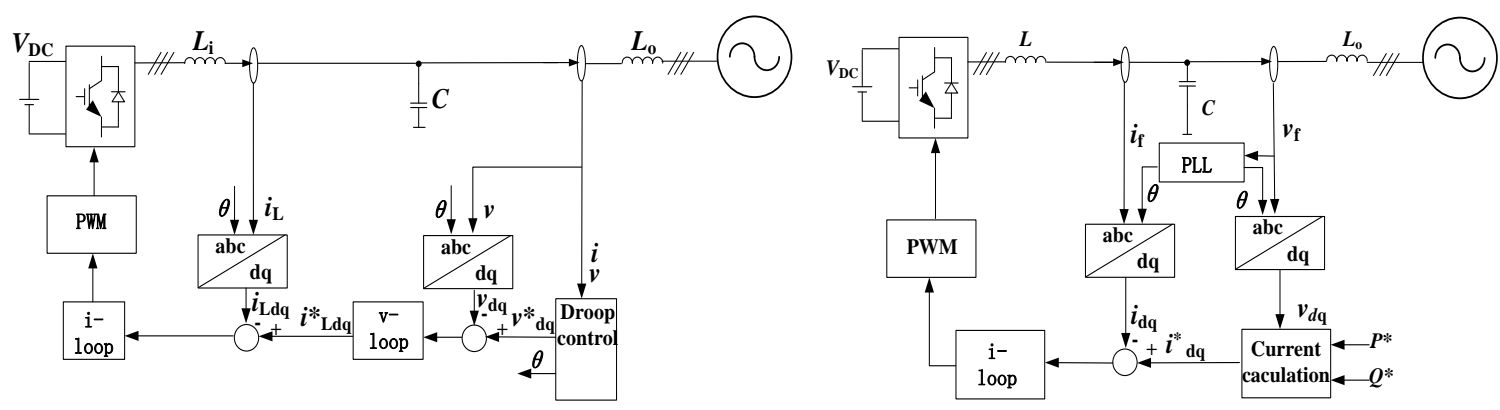

Fig. 1 Control Structure for VSC-MC and CSC-MC

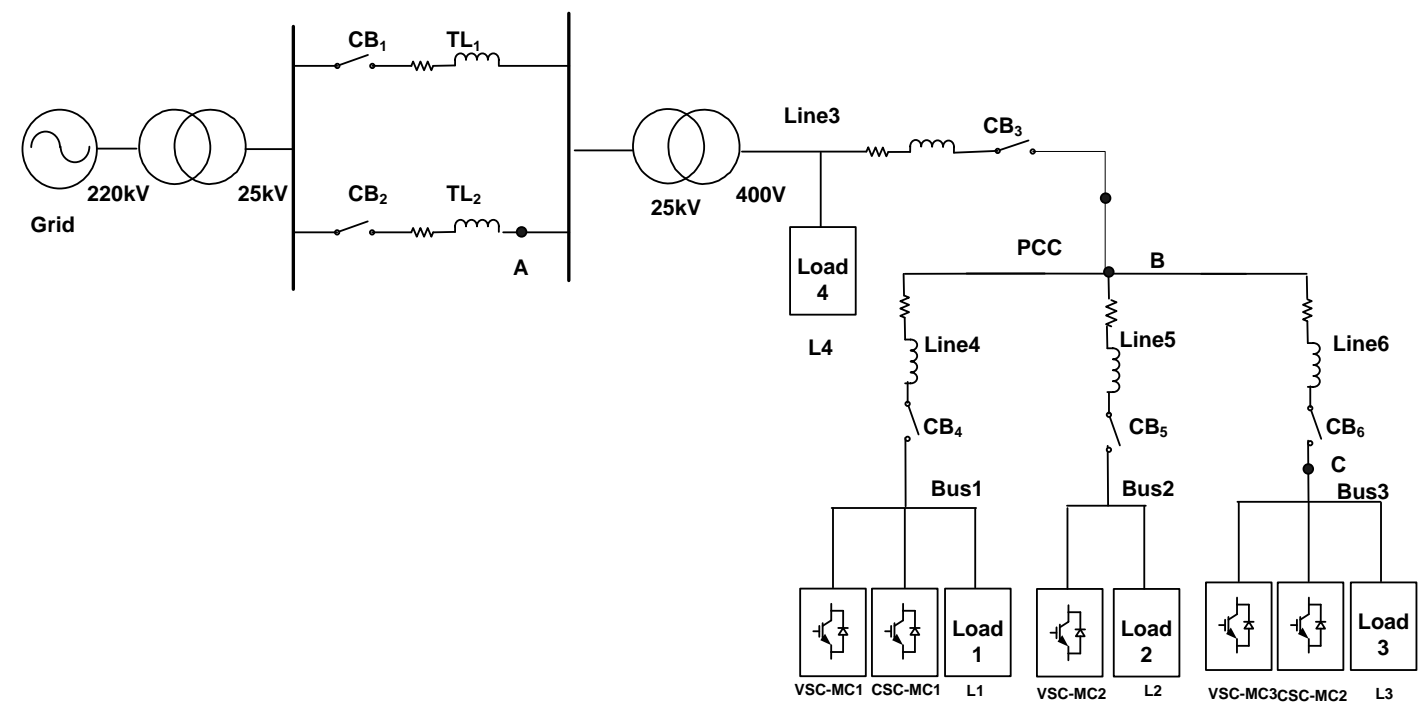

Fig. 2 Topology of Micro-grid

\section{The Stability Analysis of VSC-MC}

In a micro-grid, the VSC-MC usually offers frequency and voltage control, so the VSC-MC stability has much effect on the micro-grid stability.

According to paper[4-6], we can get the equivalent circuit of one VSC-MC connect to the grid shown as Fig.3.

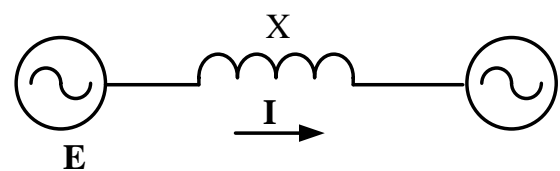

Fig. 3 Equivalent Circuit of One VSC-MC Connect to the grid

In this figure, E represents the three phase AC output voltage vector for VSC-MC, V represents the three-phase AC grid voltage vector, Xd represents the Output filter inductance for VSC-MC, I represents the three phase AC output current vector for VSC-MC. Based on Fig.3, we can get the vectors relationship shown as Fig.4.

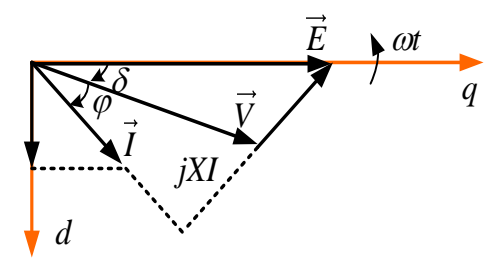

Fig. 4 VSC-MC Vectors Relationship 
In this figure, orepresents the angle between $\mathrm{E}$ and $\mathrm{V}$, prepresents the angle between $\mathrm{V}$ and $\mathrm{I}$, dq represents the rotating reference frame, $\omega r$ represents the frequency of rotating reference frame. According to Fig.3 and Fig.4 we can get equation (1).

$$
\begin{aligned}
& P_{V}=V I \cos \phi=\frac{E V}{X} \sin \delta \\
& Q_{V}=V I \sin \phi=\frac{E V}{X} \cos \delta-\frac{V^{2}}{X}
\end{aligned}
$$

According to (1), we can get the power curve shown as Fig.5.

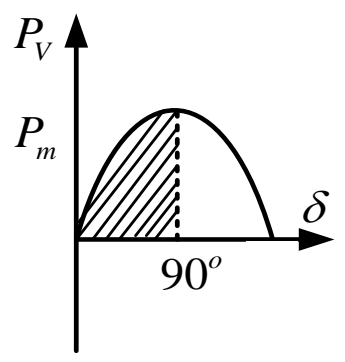

Fig. 5 Power Curve of VSC-MC

Based on the VSC-MC control strategy, we can get that when the load increase, the VSC-MC will increase $\delta$ to maintain the load. From Figure 6 we can get that when $\delta$ increase from $0^{\circ}$ to $90^{\circ}$, the output power increase. When $\delta$ become bigger than $90^{\circ}$, the output power will decrease. So we can conclude that when the control makes $\delta$ become bigger than $90^{\circ}$, the VSC-MC become unstable, and $\delta$ is the key parameter to the VSC-MC stability.

\section{Analysis Based on Simulation}

In order to research the stability of micro-grid under grid fault condition, the different fault position is considered, each position includes 3 fault cases. The simulating parameters are listed in Table1 to Table3.

Table 1 Simulating condition of case 1 to case 3

\begin{tabular}{|c|c|c|c|}
\hline Case Number & Case1 & Case2 & Case3 \\
\hline Fault Location & A & A & A \\
\hline Fault Type & $\begin{array}{c}\text { Singe Phase to } \\
\text { Earth Fault }\end{array}$ & $\begin{array}{c}\text { Double Phase } \\
\text { Earth Fault }\end{array}$ & $\begin{array}{c}\text { Three Phase } \\
\text { Earth Fault }\end{array}$ \\
\hline $\begin{array}{c}\text { Whether } \\
\text { Islanding }\end{array}$ & No & No & No \\
\hline
\end{tabular}

Table 2 Simulating condition of case 1 to case 3

\begin{tabular}{|c|c|c|c|}
\hline Case Number & Case4 & Case5 & Case6 \\
\hline Fault Location & B & B & B \\
\hline Fault Type & $\begin{array}{c}\text { Singe Phase to } \\
\text { Earth Fault }\end{array}$ & $\begin{array}{c}\text { Double Phase } \\
\text { Earth Fault }\end{array}$ & $\begin{array}{c}\text { Three Phase } \\
\text { Earth Fault }\end{array}$ \\
\hline $\begin{array}{c}\text { Whether } \\
\text { Islanding }\end{array}$ & Yes & Yes & Yes \\
\hline
\end{tabular}


Table 3 Simulating condition of case 1 to case 3

\begin{tabular}{|c|c|c|c|}
\hline Case Number & Case7 & Case8 & Case9 \\
\hline Fault Location & C & C & C \\
\hline Fault Type & $\begin{array}{c}\text { Singe Phase to } \\
\text { Earth Fault }\end{array}$ & $\begin{array}{c}\text { Double Phase } \\
\text { Earth Fault }\end{array}$ & $\begin{array}{c}\text { Three Phase } \\
\text { Earth Fault }\end{array}$ \\
\hline $\begin{array}{c}\text { Whether } \\
\text { Islanding }\end{array}$ & No & No & No \\
\hline
\end{tabular}

The simulating results of case1 to case3 are shown in Fig.6.
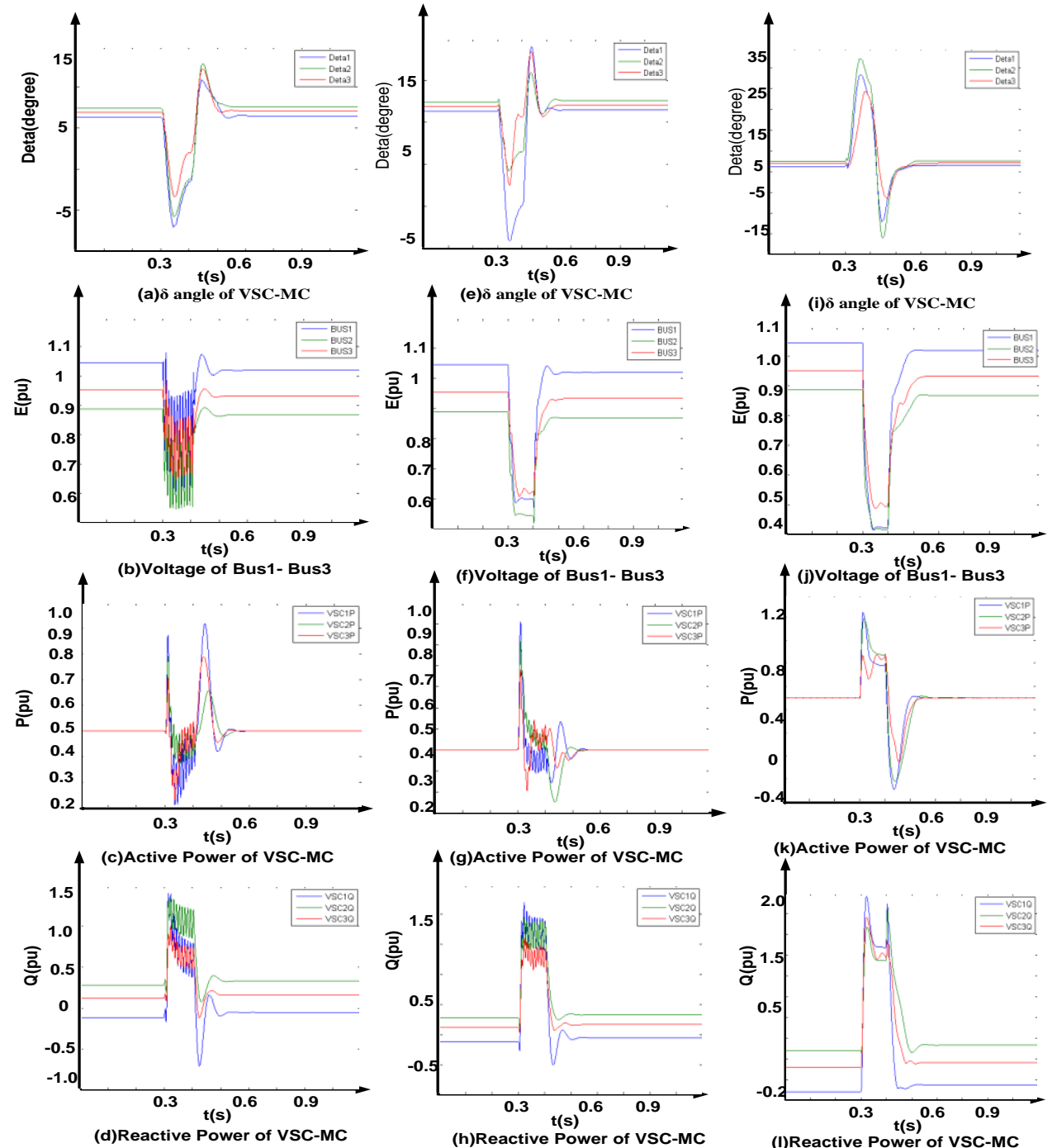

Fig. 6 Simulating Result of Case 1 to Case 3

From Fig6. (a) and Fig.6(e) we can see that during the one phase and two phase grid fault affect node A, the value off for all the VSC-MC become oscillation, and after the grid fault clearing, the value of $\delta$ for all the VSC-MC become overshoot, which make the stability margin oforeducing. From Fig.6 (i) we can see that during the three phase grid fault condition, the value offor all the VSC-MC become overshoot, which cause the stability margin offreducing, and after the grid fault, the value of bbecome oscillation. Compare Fig.6(b), Fig6. (f) and Fig.6 (j) we can see that during the grid fault condition, the voltage of BUS1 is most affect, and the value of for VSC-MC connecting with BUS1 is most affect. From Fig.6 (a) to Fig.6(1) we can see that after fault clearing, the stability margin of $\delta$ unchanged.

The simulating results of case4 to case6are shown in Fig.7. 

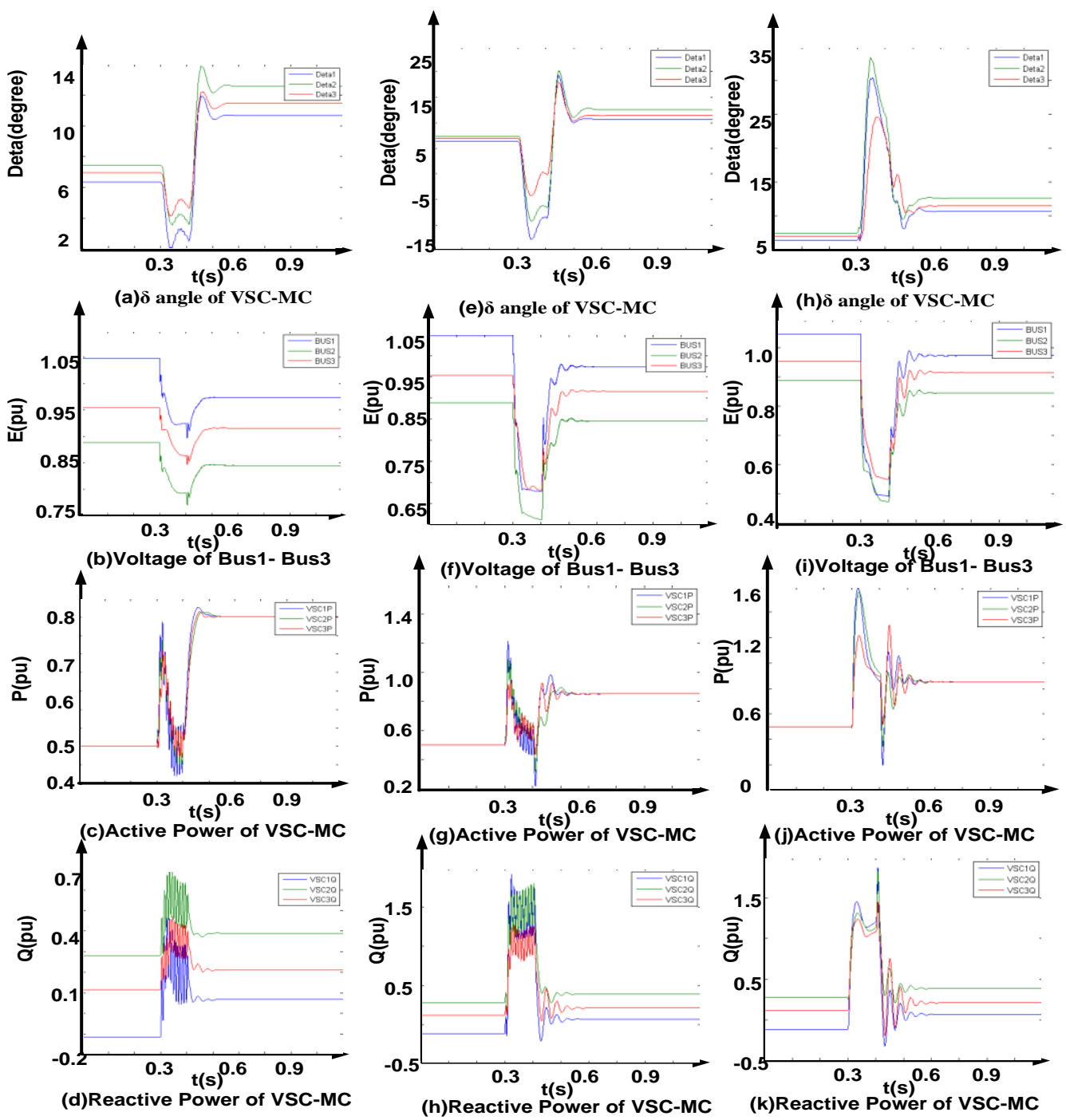

Fig. 7 Simulating Result of case 4 to Case 6

From Fig.7(a) and Fig.7(e) we can see that during the one phase and two phase grid fault affect node B, the value of $\delta$ for all the VSC-MC become oscillation, and after the grid fault clearing, the value of $\delta$ for all the VSC-MC become overshoot, which make the stability margin oforeducing. From Fig.7 (i) we can see that during the three phase grid fault condition, the value of for all the VSC-MC become overshoot, which cause the stability margin offreducing, and after the grid fault, the value offbecome oscillation. Compare Fig.7 (b), Fig.7 (f) and Fig.7(j) we can see that during the grid fault condition, the voltage of BUS1 is most affect, and the value of for VSC-MC connecting with BUS1 is most affect. From Fig.7(a) to Fig.7(1) we can see that after fault clearing, all the BUS voltage are reducing, the stability margin of $\delta$ for all the VSC-MC are also reducing, and the active power and reactive power of all the VSC-MC are increasing. 

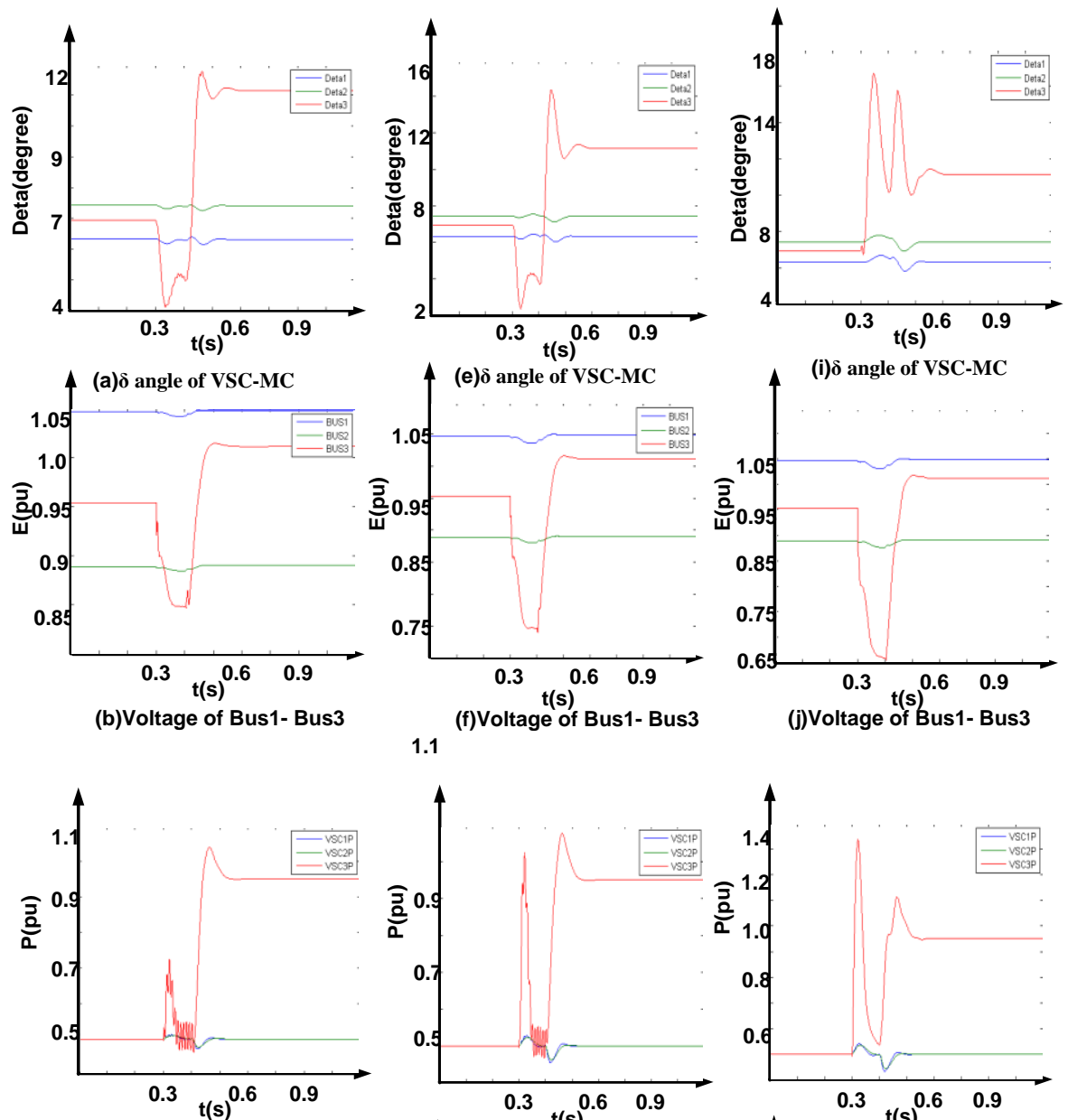
1.1

(j)Voltage of Bus1- Bus3
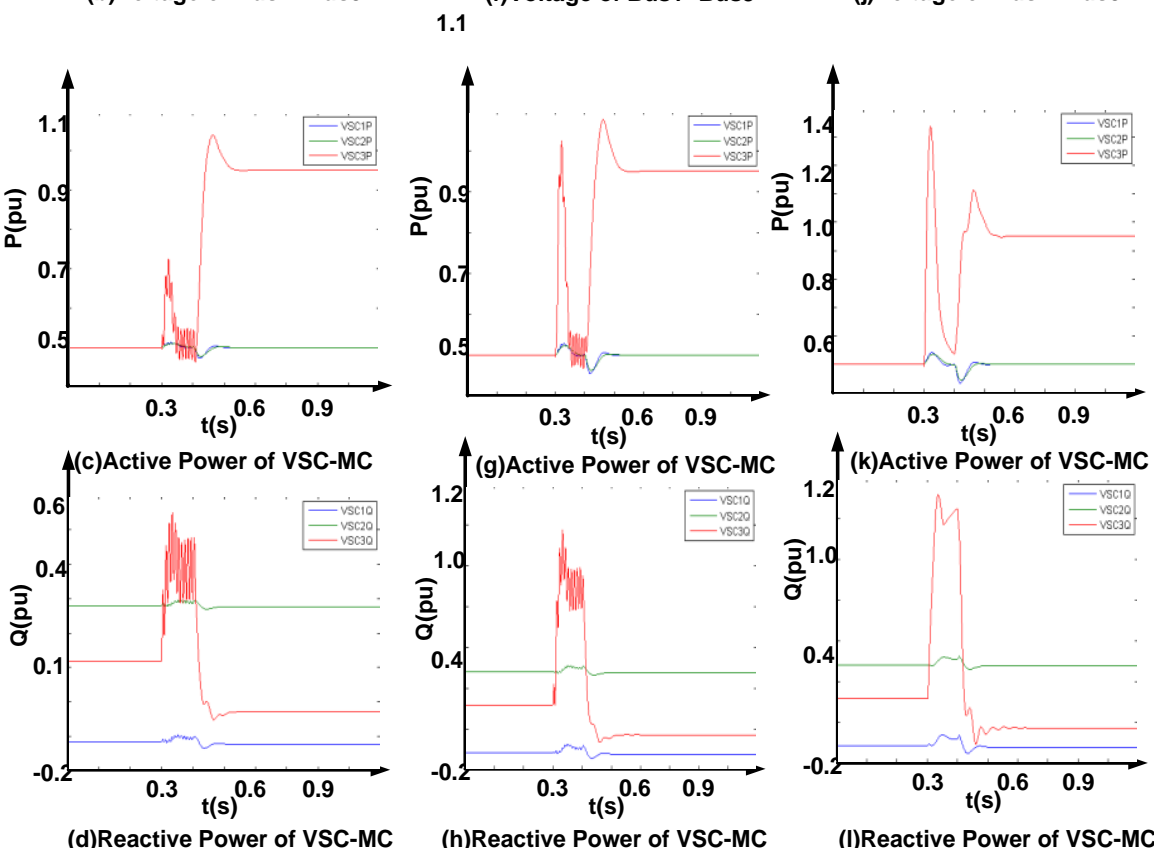

Fig. 8 Simulating Result of Case 7 to Case 9

From Fig.8(a) and Fig.8 (e) we can see that during the one phase and two phase grid fault affect node C, the value of $\delta$ for VSC-MC3 become oscillation, and after the grid fault clearing, the value of $\delta$ for VSC-MC3 become overshoot, which make the stability margin offreducing. From Fig.8 (i) we can see that during the three phase grid fault condition, the value of $\delta$ for VSC-MC3 become overshoot, which cause the stability margin offreducing, and after the grid fault, the value of $\delta$ become oscillation. From Fig.8 (a) to Fig.8 (1) we can see that after fault clearing, the voltage of BUS3 is increasing, the stability margin of for VSC-MC3 is also reducing, and the active power and reactive power of VSC-MC3 is increasing.

\section{Summary}

The micro-grid frequency and voltage are controlled by VSC-MC. The performance of VSC-MC is affect by the value of power angle $\delta$. The simulation results indicate that when the fault is occur at the main grid, all the VSC-MC in micro-grid will be affected, and the react of $\delta$ is related to the fault type. When the fault 
is occur at the micro-grid, only the VSC-MC connected with the fault line is affected, and the react of is related to the fault type.

\section{Acknowledgement}

Supported by the Beijing Education Commission R\&D program (Grant No. KM20161005009), and Postdoctoral research activities in Beijing (Grant No. 1000200273).

\section{References}

[1] Rocabert J, Luna A, Blaabjerg F, et al. Control of Power Converters in AC Microgrids[J]. Power Electronics, IEEE Transactions on, 2012, 27(11):4734-4749.

[2] Mohamed Y A R I, Zeineldin H H, Salama M M A, et al. Seamless Formation and Robust Control of Distributed Generation Microgrids via Direct Voltage Control and Optimized Dynamic Power Sharing[J]. Power Electronics, IEEE Transactions on, 2012,27(3):1283-1294.

[3] Fei W, Duarte J L, Hendrix M A M. Grid-Interfacing Converter Systems With Enhanced Voltage Quality for Microgrid Application\&\#x2014;Concept and Implementation[J]. Power Electronics, IEEE Transactions on, 2011, 26(12):3501-3513.

[4] Guerrero J M, Matas J, Luis G D V, et al. Decentralized Control for Parallel Operation of Distributed Generation Inverters Using Resistive Output Impedance[J]. Industrial Electronics, IEEE Transactions on, 2007, 54(2):994-1004.

[5] Barklund E, Pogaku N, Prodanovic M, et al. Energy Management in Autonomous Microgrid Using Stability-Constrained Droop Control of Inverters[J]. Power Electronics, IEEE Transactions on, 2008, 23(5):2346-2352.

[6] Jinwei H, Yun W L, Guerrero J M, et al. An Islanding Microgrid Power Sharing Approach Using Enhanced Virtual Impedance Control Scheme[J]. Power Electronics, IEEE Transactions on, 2013, 28(11):5272-5282.

[7] Ma Tianyi, Jin Xinmin, Huang Xing Modeling and Stability Analysis of Microgrid with Multiple Converters[J]. Automation of Electric Power System. 2012, 36(14): 136-142. 